\title{
ANÁLISE DE QUALIDADE DO DIESEL COMERCIAL BRASILEIRO EM CAMPO
}

Christian M. Wahnfried e Larissa Ap. Kazumy Koketsu.

Robert Bosch Ltda.

E-Mails: Christian.Wahnfried@br.bosch.com, fixed-term.Larissa.Koketsu@br.bosch.com

\begin{abstract}
RESUMO
As falhas em motores e veículos devido a desvios de qualidade no diesel comercial têm sido um tema cada vez mais recorrente e mais frequente nos serviços autorizados de montadoras e de sistemistas. Temas como o Rota2030, PROCONVE P8 e Renovabio trazem a necessidade do desenvolvimento de novas tecnologias automotivas em um cenário de crescimento acelerado do uso de biodiesel a níveis inéditos, considerando os grandes mercados mundiais. O desafio é compatibilizar este cenário com as tecnologias de alta precisão e com requisitos de durabilidade estendidos necessários ao Rota2030 e PROCONVE P8. Neste trabalho, o resultado mais recente da análise de amostras de diesel comercial B10 coletadas em 45 postos de abastecimento em 2018 é analisado, comparando-o a análises passadas e procurando estabelecer uma correlação com as falhas mais frequentes apresentadas por veículos.
\end{abstract}

Palavras-chave: Diesel comercial, biodiesel, análise de qualidade, falhas de campo

\section{INTRODUÇÃO}

O tema sustentabilidade vêm ganhando grande destaque nos últimos anos, aumentando cada vez mais espaço na definição de políticas públicas. Neste sentido, novas legislações e programas estão sendo implementados pelo governo brasileiro para atendimento às metas de redução de pegada de carbono acordadas no Acordo de Paris - COP21. O ROTA2030, tem como principais pontos, a implementação de metas de eficiência energética, incentivos fiscais para o desenvolvimento de tecnologias locais e para veículos híbridos e elétricos. Já o Renovabio, visa especificamente a ampliação do uso de combustíveis renováveis na matriz energética brasileira através da emissão de créditos de carbono negociáveis no mercado aberto. Em paralelo, o IBAMA recentemente definiu as novas fases L7, L8 e P8 do PROCONVE, que visam diminuir de modo intenso os limites de emissões.

A lei n¹3.263 [1], criada em 2016, demandou a realização de testes com as misturas B10 e B15 de biodiesel. Os testes definidos pelo Sindipeças e Anfavea, consolidados pela AEA, foram realizados com as misturas fornecidas pelas associações de produtores de biodiesel via a BR Distribuidora. Os testes com B10, encerrados em fevereiro de 2018, foram bem-sucedidos, mas com algumas sugestões de melhorias com relação à especificação [2]. Já os testes com B15, finalizadas em janeiro de 2019, apresentaram resultados positivos com pontos de atenção nos testes do Sindipeças e alguns resultados negativos por parte da Anfavea, prevalecendo assim, a reprovação desta mistura sobretudo devido a questões de estabilidade à oxidação e consequente geração de depósitos no sistema de combustível [3].

Estudo feito com frotistas e caminhoneiros autônomos (BOSCH E CHETOCHINE, 2019) tornou evidente que o custo do combustível é o item mais importante nas despesas destes. Cerca 
de um terço dos 400 entrevistados indica que a qualidade do diesel piorou nos últimos 5 anos, apontando aumento no entupimento de filtros, quantidade de água no combustível e maior despesa em manutenção.

Assim, ficam evidentes os desafios de compatibilizar todos estes cenários com a qualidade do diesel comercial e com a necessidade de adequar as especificações pertinentes de forma a garantir que o usuário final não tenha problemas em seu equipamento.

\section{INFORMAÇÕES GERAIS}

A SGS (Société Générale de Surveillance), fundada em 1878, é uma empresa voltada a testes e verificações [4], entre elas a coleta e análise de amostras de combustíveis em dezenas de países. A Bosch faz a aquisição dos dados, duas vezes ao ano, das pesquisas voltadas à qualidade do diesel, gasolina e etanol.

O objetivo deste trabalho é apresentar a pesquisa mais recente da qualidade do diesel feita pela SGS em 2018 [5] e compara-la com pesquisas adquiridas em anos anteriores, identificando tendências com o passar dos anos e estabelecendo correlações entre estes estudos com os problemas de campos.

Dentro da pesquisa estão inclusas 45 amostras divididas em óleo diesel S10 e S500 de 13 estados brasileiros (figura 1), que foram coletadas em postos com bandeira e sem bandeira.

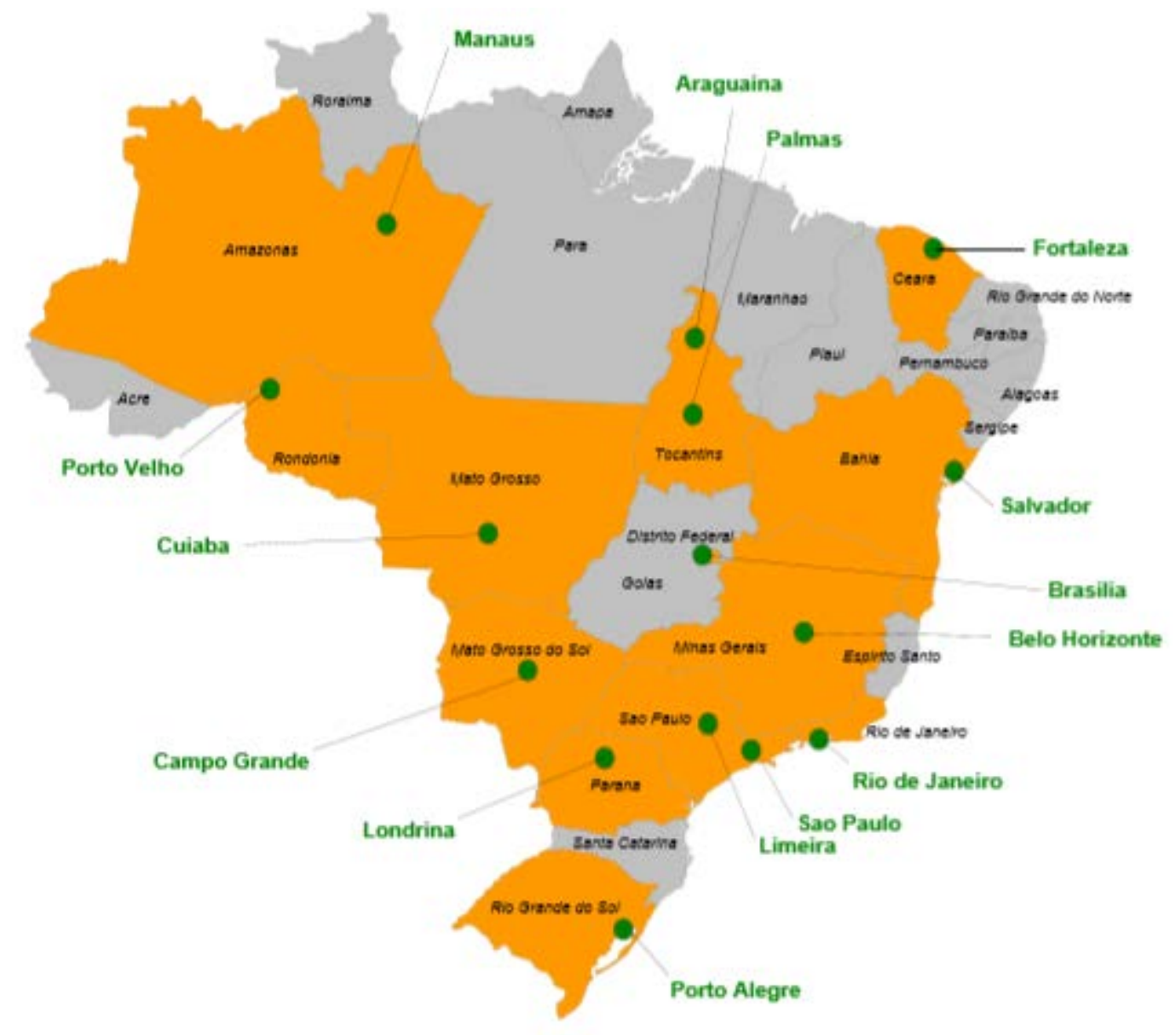

Fonte: SGS

Figura 1- Mapa dos estados brasileiros em que a pesquisa foi feita. 
A tabela abaixo traz a quantidade de amostras por tipo de diesel e de biodiesel utilizado na mistura para as regiões do Brasil.

\begin{tabular}{|c|c|c|c|c|c|c|}
\hline Região & Estado & Amostras & S10 & S500 & Sebo+Soja & Soja \\
\hline \multirow{2}{*}{ Sul } & Paraná & 3 & 1 & 2 & 2 & 1 \\
\hline & Rio Grande do Sul & 3 & 1 & 2 & 2 & 1 \\
\hline \multirow{3}{*}{ Sudeste } & Minas Gerais & 3 & 2 & 1 & 2 & 1 \\
\hline & Rio de Janeiro & 3 & 1 & 2 & 0 & 3 \\
\hline & São Paulo & 6 & 2 & 4 & 4 & 2 \\
\hline \multirow{3}{*}{$\begin{array}{l}\text { Centro } \\
\text { Oeste }\end{array}$} & Distrito Federal & 3 & 2 & 1 & 1 & 2 \\
\hline & Mato Grosso & 3 & 1 & 2 & 1 & 2 \\
\hline & $\begin{array}{l}\text { Mato Grosso do } \\
\text { Sul }\end{array}$ & 3 & 1 & 2 & 1 & 2 \\
\hline \multirow{3}{*}{ Norte } & Amazonas & 3 & 1 & 2 & 0 & 3 \\
\hline & Rondônia & 3 & 1 & 2 & 0 & 3 \\
\hline & Tocantins & 6 & 2 & 4 & 0 & 6 \\
\hline \multirow{3}{*}{ Nordeste } & Bahia & 3 & 1 & 2 & 2 & 1 \\
\hline & Ceará & 3 & 3 & 0 & 3 & 0 \\
\hline & Total & 45 & 19 & 26 & 18 & 27 \\
\hline
\end{tabular}

Figura 2- Tabela com amostras analisadas.

Devido à metodologia analítica empregada, não foi possível determinar o percentual de sebo misturado na soja.

Dentre as propriedades analisadas estão todas aquelas especificadas pela resolução do diesel comercial tais como:

- Densidade;

- Viscosidade;

- Propriedades a frio;

- Estabilidade à oxidação;

- Curva de destilação;

- Cetano (índice e número);

- Enxofre;

- Lubricidade;

- Aromáticos;

- Conteúdo de Biodiesel;

- Água;
- Partículas sólidas;

- Localidade de coleta;

- Tipo de diesel;

- Preço;

- Aparência;

- Metais e Íons metálicos;

- Distribuição do Éster;

- Especificação ANP;

- Bandeira do posto;

- Ponto de fulgor

Neste trabalho serão analisadas as principais propriedades com potencial influência sobre o sistema de combustível e a tendência destas ao longo dos últimos anos.

Os gráficos mostrados a seguir trazem as seguintes informações:

- O eixo vertical está na unidade indicada no título do gráfico, p.ex. $\mathrm{mm}^{2} / \mathrm{s}$ no caso do gráfico na figura 3. 
- O eixo horizontal traz o histórico dos resultados das pesquisas realizadas no Brasil, onde MV significa mean value ou valor médio e o número indica o ano de coleta das amostras. Por exemplo MV 18 é o resumo dos resultados para o ano de 2018.

- As barras dos gráficos indicam a média dos resultados daquele ano, enquanto os traços superior e inferior dentro da barra indicam os respectivos valores máximos e mínimos encontrados.

- As linhas tracejadas em verde indicam graficamente os limites inferior e superior da especificação do diesel comercial S10 e S500 conforme Resolução 50/2013 da ANP Agência Nacional de Petróleo, Gás Natural e Biocombustíveis. Este limite é mostrado na caixa de texto no canto superior direito de cada gráfico.

- Viscosidade à $40^{\circ} \mathrm{C}\left[\mathrm{mm}^{2} / \mathrm{s}\right]$ - ASTM D 445

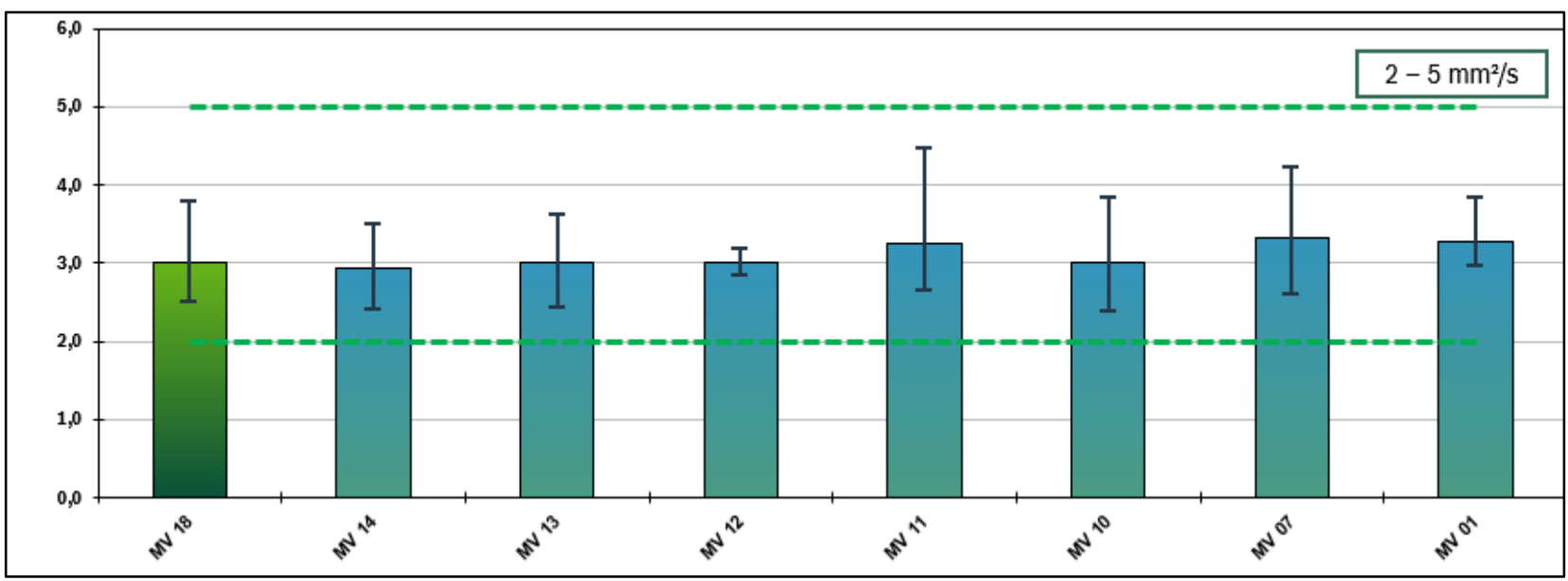

Fonte: SGS

Figura 3 - Análise da viscosidade do Diesel entre os anos 2001 e 2018

Viscosidade define-se como a resistência de um fluído ao escoamento em uma determinada temperatura [4].

Nas últimas três pesquisas, é notável que a variação entre os resultados é pequena e bem próximo à média da especificação.

A viscosidade tem importância fundamental na tribologia, ou seja, na lubrificação do sistema de injeção diesel lubrificado pelo combustível. Para garantir a correta lubrificação dos pares tribológicos no sistema de injeção, por exemplo came e rolete, a viscosidade deve ter valores dentro da especificação estabelecida. Neste sentido, tanto o resultado da pesquisa quanto a experiência de campo nos serviços autorizados da Bosch demonstram não haver problemas com esta propriedade dada a ausência de desgaste por falta de lubrificação. 
- Densidade a $15^{\circ} \mathrm{C}\left[\mathrm{kg} / \mathrm{m}^{3}\right]$ - ASTM D 4052

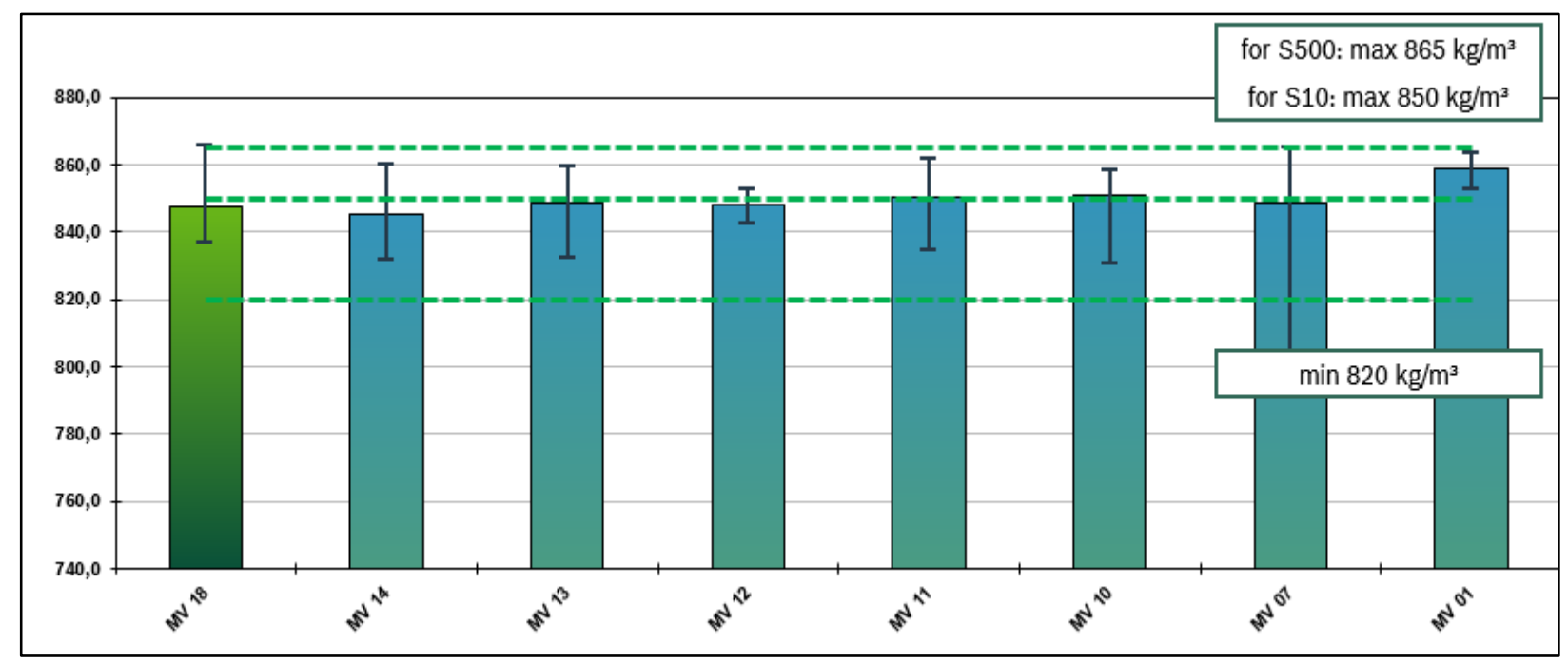

Fonte: SGS

Figura 4 - Análise da densidade do Diesel entre os anos 2001 e 2018

Densidade, em termos de combustão, é diretamente proporcional ao quanto de energia que está sendo injetada no cilindro [4]. Com a mudança do teor de enxofre de 500 ppm para 10 ppm há uma diminuição no limite da densidade em $15 \mathrm{~kg} / \mathrm{m}^{3}$. Entretanto, como visto na figura 4, não houve uma variação significativa da densidade desde a introdução do diesel S10 em 2013, em conjunto com a introdução das fases PROCONVE L6 e P7 em 2012.

No caso das bombas injetoras que dosam o combustível em volume, como os sistemas mecânicos, Unit Pump e Unit Injector, combustíveis de maior ou menor densidade produzem respectivamente maiores ou menores valores de potência e fumaça. A densidade também influencia a compressibilidade do diesel, atuando na pressão de injeção diretamente. Este é um ponto de atenção ao aumento do conteúdo de biodiesel, cuja densidade é maior que a do diesel de petróleo. Porém, conforme resultados da pesquisa, a densidade encontra-se dentro dos limites especificados e assim seguros para o sistema de injeção.

- $\quad$ Lubricidade a $60^{\circ} \mathrm{C}[\mu \mathrm{m}]$ - EN ISO 12156

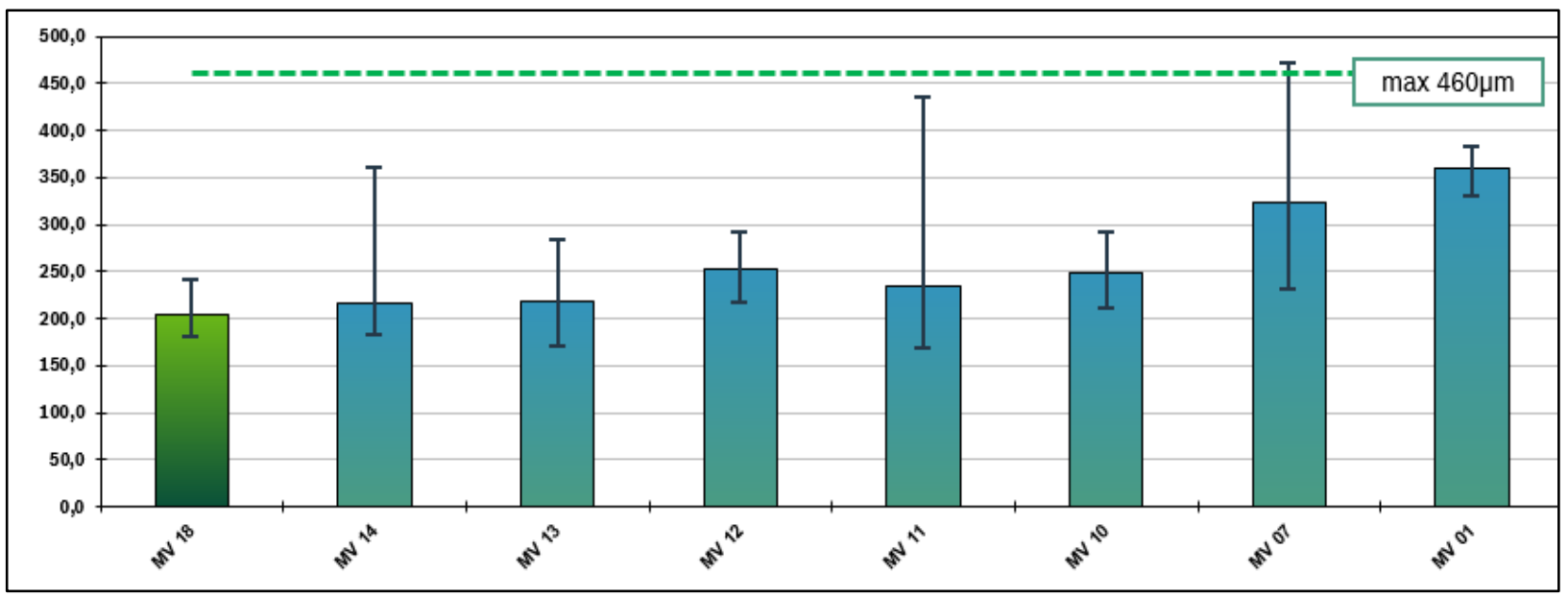

Figura 5 - Análise da lubricidade do Diesel entre os anos 2001 e 2018

Fonte: SGS 
A lubricidade é um termo qualitativo que descreve a habilidade de um combustível em evitar a friç̧ão e o desgaste entre superfícies metálicas em movimento relativo sob carga [7].

De forma análoga, à viscosidade, tem papel fundamental em garantir a correta lubrificação dos pares tribológicos no sistema de injeção.

O combustível com deficiência de lubricidade afeta o sistema de injeção. A falta de lubrificação entre as partes móveis da bomba, sobretudo sistemas Common Rail, apresenta como consequência o desgaste em peças altamente solicitadas até o prejuízo da função gerando uma falha total.

Os dados da pesquisa (figura 5) mostram que mesmo com a transição entre S500 e S10, não há alterações significativas da lubricidade, sobretudo, devido à maior participação do biodiesel no diesel comercial, já que este possui uma maior lubricidade.
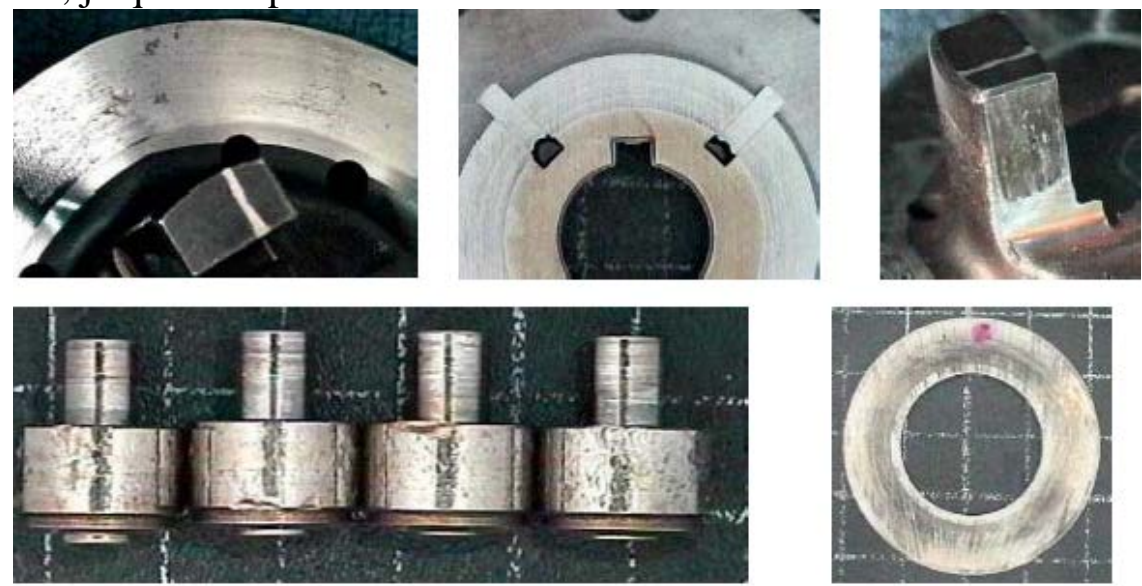

Fonte: Bosch

Figura 6 - Desgaste de componentes do sistema de injeção após 1000h de teste em bancada com diesel de baixa lubricidade [7]

- Água (Karl Fischer) [mg/kg] - ASTM D 6304

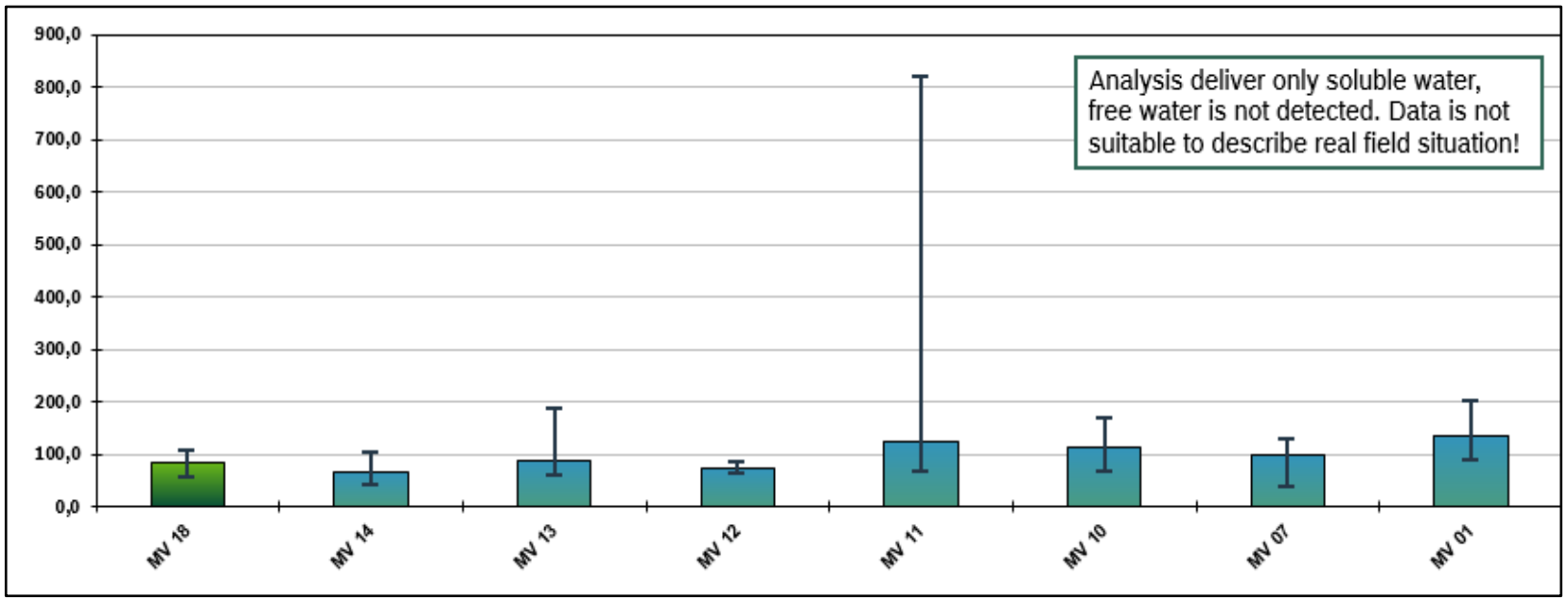

Fonte: SGS

Figura 7 - Análise da quantidade de água no Diesel entre os anos 2001 e 2018

A água é um item indesejado no diesel por seu potencial oxidativo, corroendo superfícies metálicas, e por sua baixa lubricidade. Adicionalmente pode causar o efeito de fragilização por hidrogênio, onde Hidrogênio $(H)$ penetra no material devido às solicitações mecânicas. A 
estrutura do material é “explodida”, semelhante ao congelamento da água, quando o Hidrogênio se recombina em $\mathrm{H}_{2}$ e aumenta de volume.

A água pode contaminar o combustível por inclusão direta (p. ex. respiro do tanque ou bocal inadequado) ou por condensação no tanque do posto de abastecimento ou do veículo.

Os dados da amostragem de campo demonstram baixo teor de água, porém como citado no gráfico, a análise de água não representa a realidade do campo devido a forma de coletar as amostras.

Apesar dos investimentos das montadoras em equipar os veículos com eficientes filtros separadores de água, a experiência de campo mostra que muitos usuários ignoram a necessidade de purgar a água de tais filtros. Assim a água livre se mistura ao diesel, causando danos como os expostos acima no sistema de injeção.

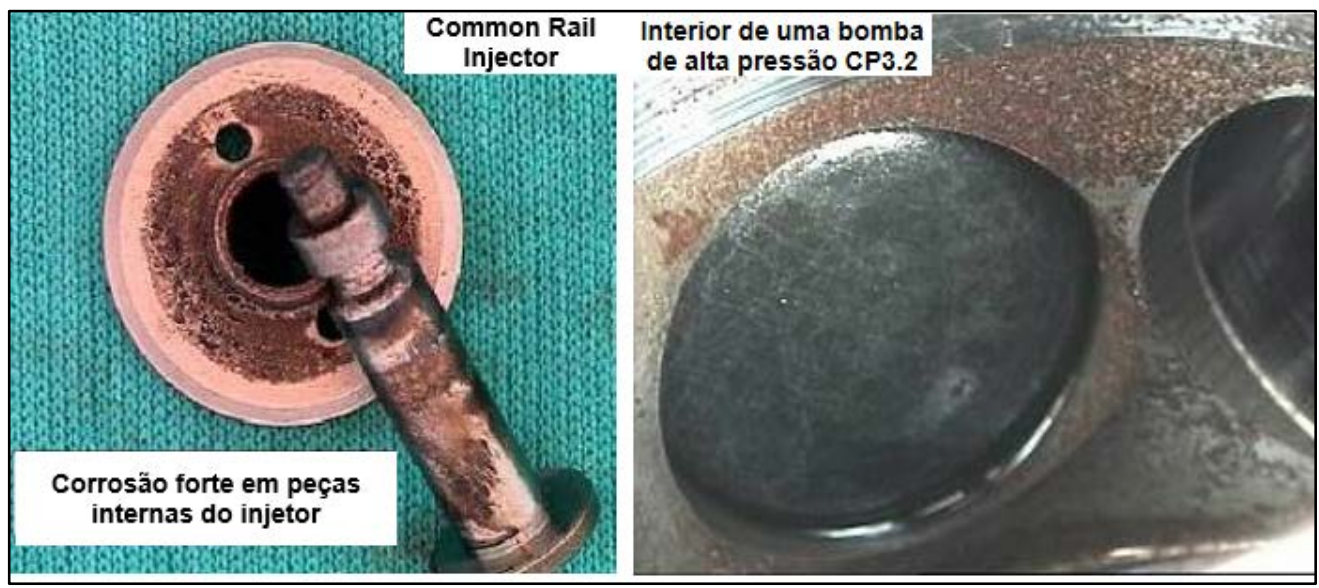

Fonte: Bosch

Figura 8- Oxidação causada pela quantidade de água no combustível.

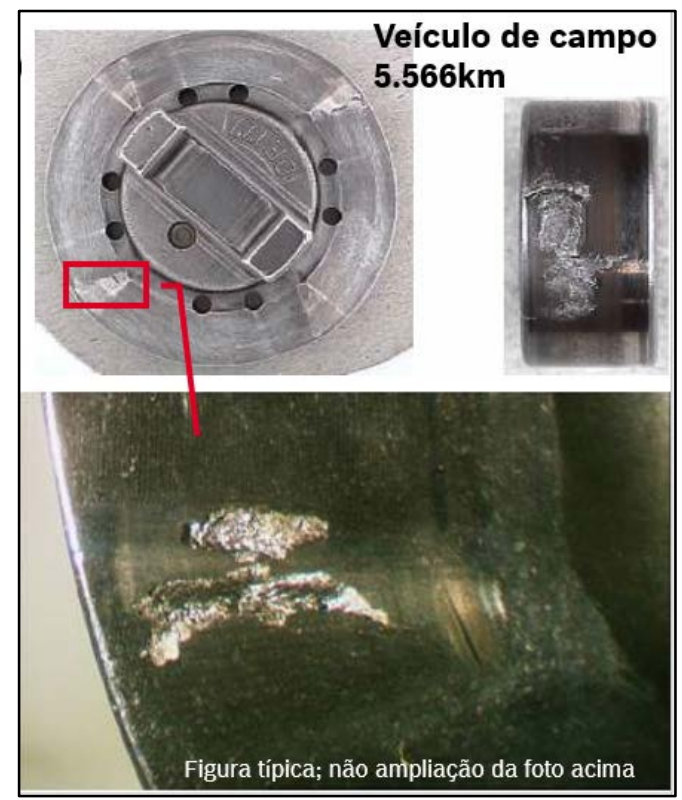

Fonte: Bosch

Figura 9- Exemplo de peças com superfície fragilizada por hidrogênio. 
- $\quad$ Número de Cetano [-] - ASTM D 613

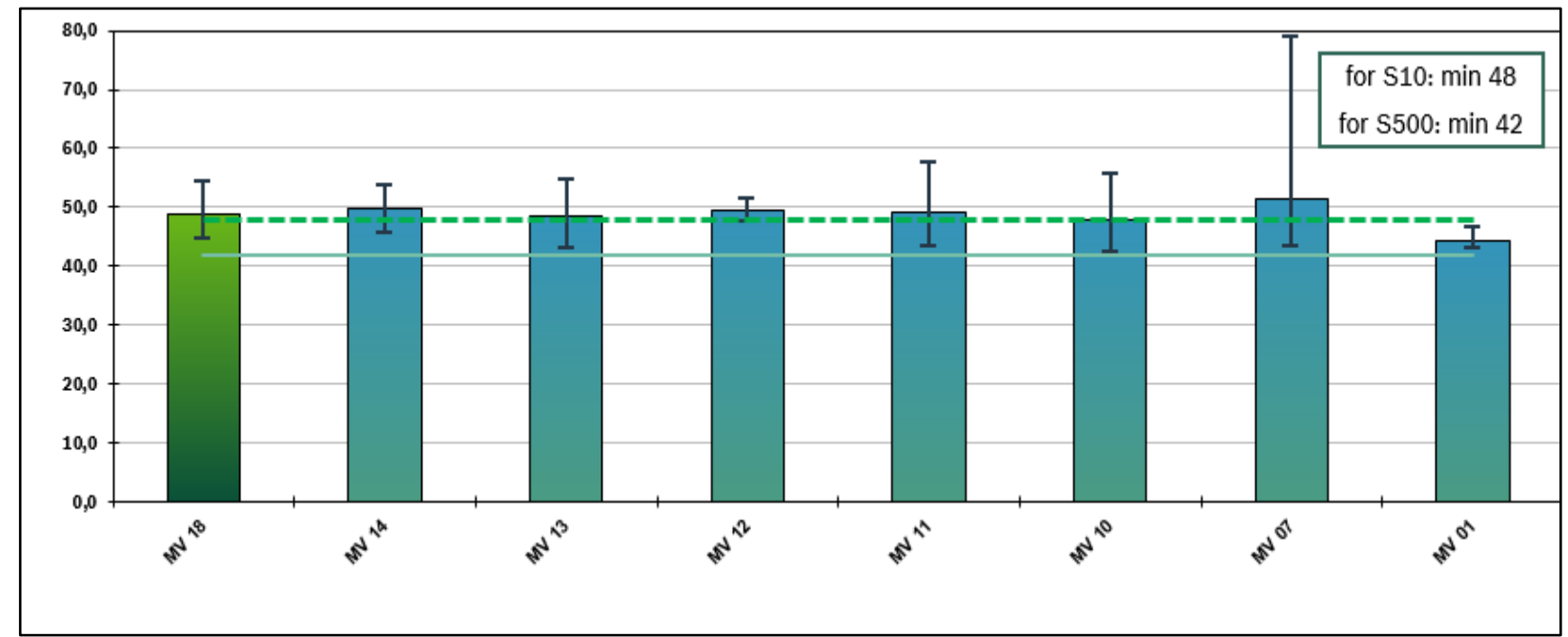

Fonte: SGS

Figura 10 - Análise do número de Cetano presente no Diesel entre os anos 2001 e 2018

Como o motor diesel funciona sem ignição externa é necessário que o combustível se inflame espontaneamente no menor tempo possível sob a ação da temperatura e pressão na câmara de combustão. A facilidade de ignição é expressa pelo número de Cetano, pois quanto maior o número de Cetano, maior facilidade de ignição terá o combustível. A escala de medição do número de Cetano foi definida através de dois parâmetros:

- N-Hexadecano (Cetano), de fácil ignição é atribuído o índice 100

- Alfa-Metil-Naftaleno, de difícil ignição é atribuído o índice zero.

O número de Cetano é medido empiricamente em um motor de teste padrão CFR operando sob as condições estabelecidas na norma ASTM D613, se o Diesel apresenta um número de Cetano igual a 45, ele apresenta o mesmo período de atraso que aquele apresentado por uma mistura de $45 \%$ de Cetano e 55\% de Alfa-Metil-Naftaleno.

Avaliando os dados da SGS (figura 10), o diesel S10 apresenta valores de 46,2 a 54,6 com média de 50 pontos. Apesar da média acima do limite mínimo de 48, há quatro de dezenove amostras abaixo deste limite. Já o S500 apresenta valores de 45 a 53,6, com média de 48 pontos, sendo o limite mínimo 42. A parcela de biodiesel pode estar contribuindo para a elevação do número de Cetano do S500-B10 devido à sua média de 60 [6].

Esta propriedade tem somente influência indireta sobre o sistema de injeção. Quando o número de Cetano é muito baixo, tende a formar maior carbonização nos bicos injetores. Porém, esta também pode ser causada por várias outras propriedades, como densidade, qualidade do biodiesel e presença de Zinco no combustível, ficando assim difícil sua correlação com reclamações de campo. 
- Destilação $\left[{ }^{\circ} \mathrm{C}\right]$ - ASTM D 86

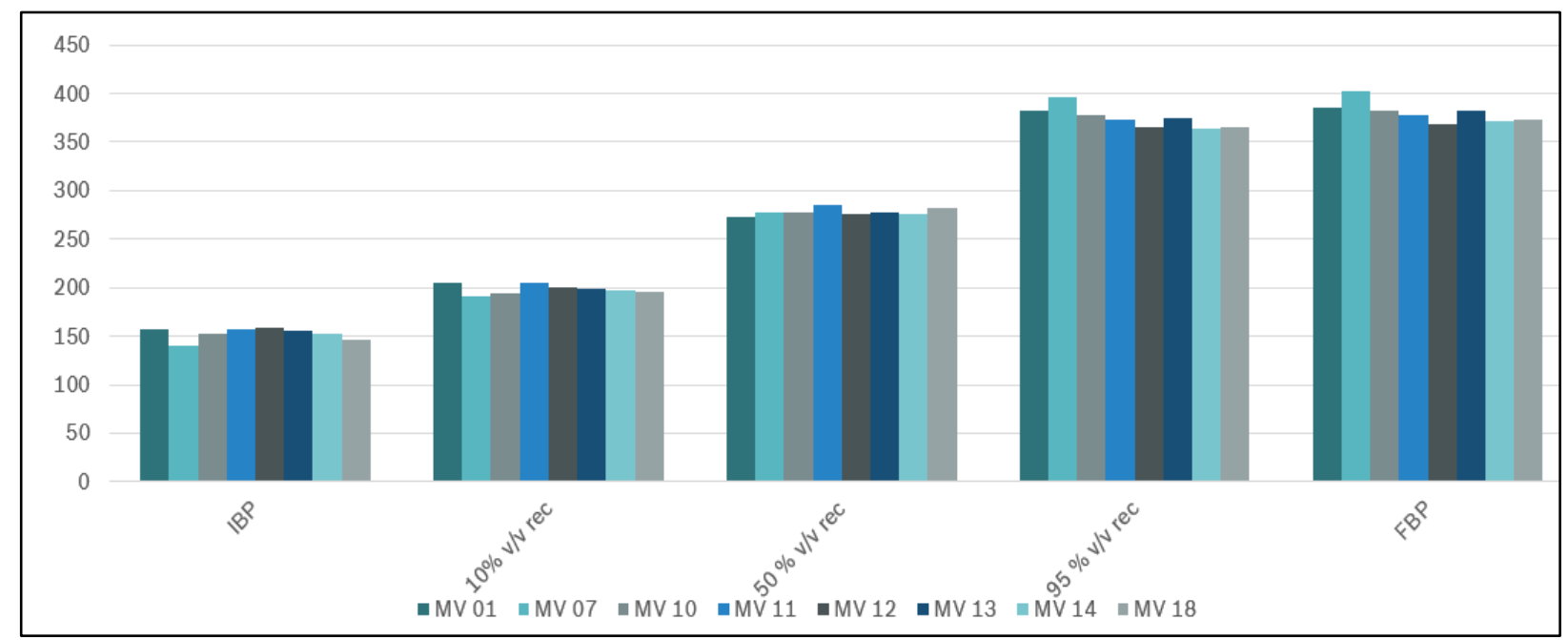

Fonte: SGS

Figura 11 - Análise da curva de destilação do Diesel entre os anos 2001 e 2018

A faixa de destilação, ou seja, a temperatura de início e fim de destilação influencia diretamente o modo de operação e as emissões dos motores. Inicio de destilação baixo implica em melhores condições de partida a frio, baixo índice de Cetano e pior capacidade de lubrificação. Fim de destilação alto implica em melhor índice de Cetano, porém piores valores de fuligem e carbonização dos bicos. Assim, fica claro o delicado equilíbrio entre o máximo aproveitamento do petróleo cru e a produção de um diesel que atenda aos limites de emissões e requisitos de durabilidade dos motores.

A evolução da especificação do óleo diesel ao longo dos anos está trazendo uma redução da curva de destilação, ou seja, o óleo diesel está ficando mais leve, permitindo uma melhor combustão e menos emissões de particulados.

A curva de destilação vem diminuindo ao passar dos anos, talvez pela maior presença do S10 na amostragem. A parcela de biodiesel, cuja destilação se dá a aprox. $330^{\circ} \mathrm{C}$, não tem uma influência aparente sobre o resultado.

Assim como o número de Cetano, esta propriedade tem somente influência indireta sobre o sistema de injeção, podendo causar maior carbonização nos bicos injetores, mas que também pode ser causada por várias outras propriedades, como densidade, qualidade do biodiesel e presença de Zinco no combustível, ficando assim difícil sua correlação com reclamações de campo. 
- Enxofre [mg/kg] - ASTM D 5453 (<10mg/kg) e ASTM D 6334 mod. (>10mg/kg)

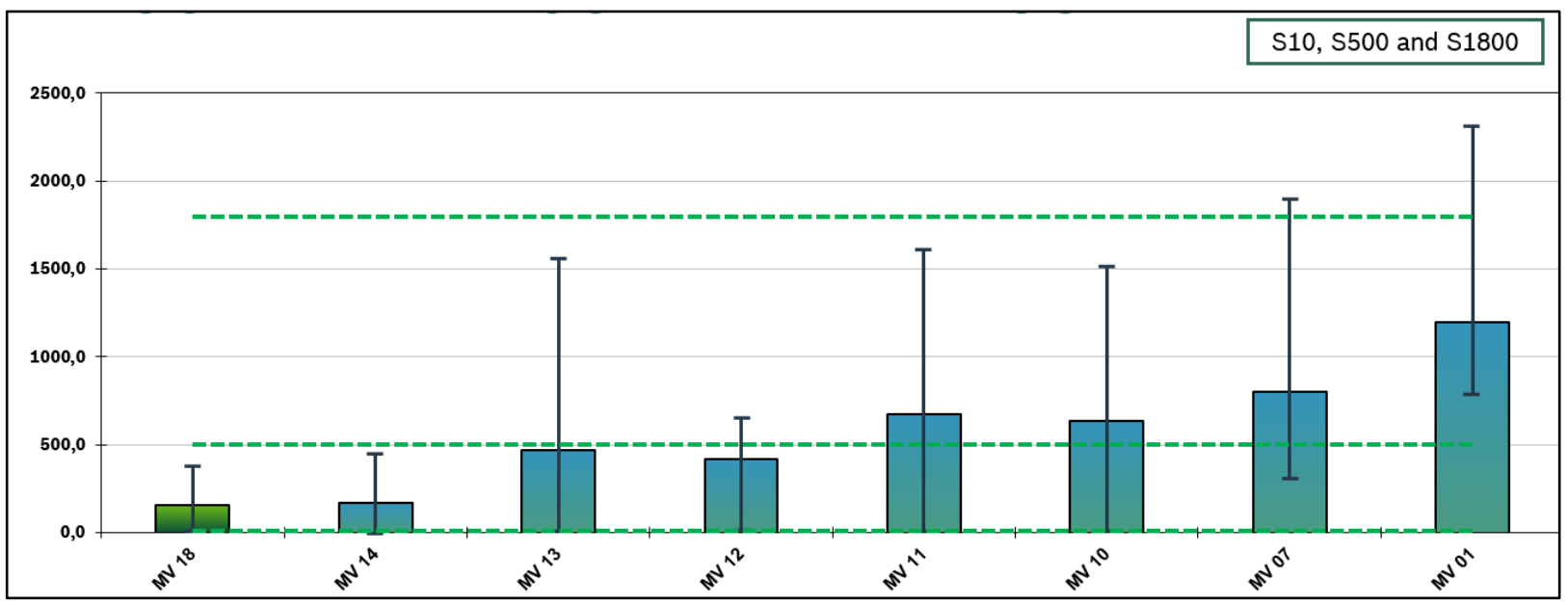

Fonte: SGS

Figura 12 - Análise do teor de enxofre no Diesel entre os anos 2001 e 2018

Conforme mostrado na figura 13, o diesel comercial teve seu conteúdo de enxofre reduzido ao longo dos anos, sobretudo em função da evolução das fases do PROCONVE. A análise dos dados da SGS (figura 12) mostra que os dados de campo refletem as transições impostas por normas.

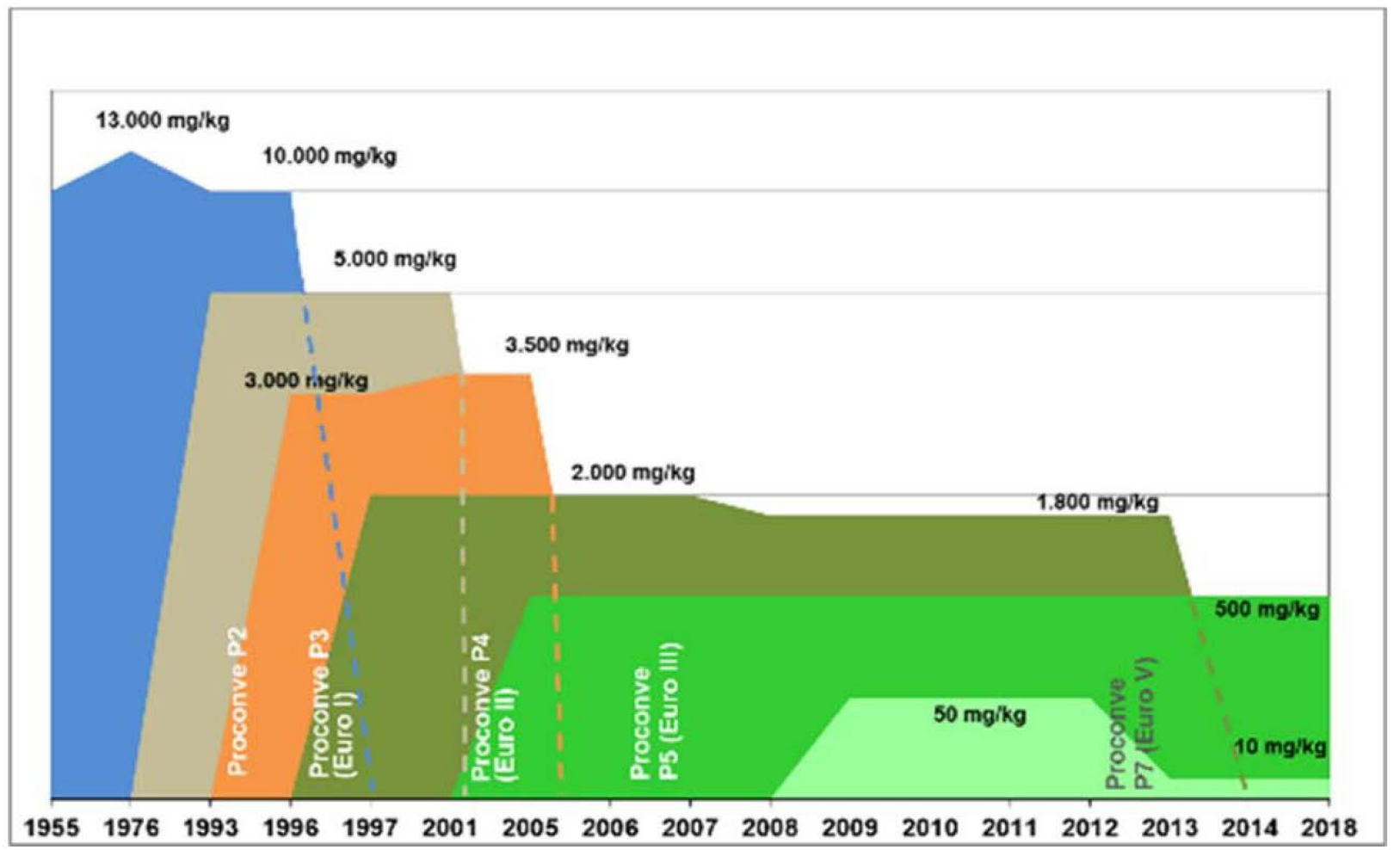

Figura 13 - Evolução do teor de enxofre no óleo diesel brasileiro 


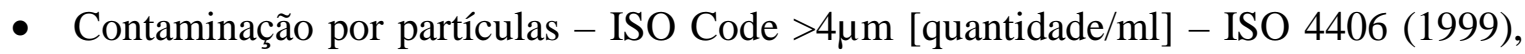
ISO 11171

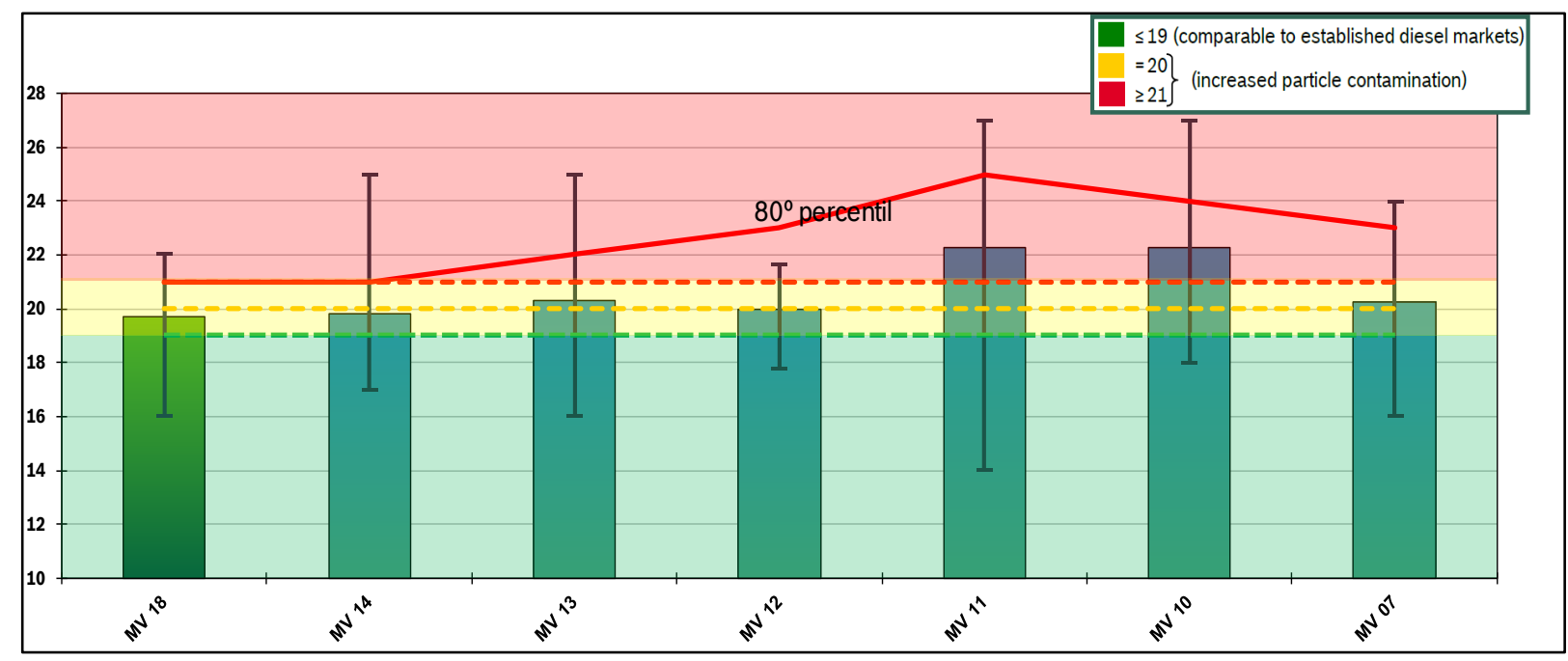

Fonte: SGS

Figura 14 - Análise da quantidade das partículas sólidas do Diesel entre os anos 2007 e 2018.

A contaminação por partículas sólidas é normal em qualquer fluído hidráulico, como o diesel comercial. Porém os sistemas de injeção diesel requerem um combustível com baixíssimo nível de contaminação, uma vez que tais partículas podem causar desgaste erosivo em superfícies de controle (como válvulas) e se alojar na folga dos componentes do sistema, causando abrasão e até travamento destes. Alguns exemplos podem ser vistos nas figuras 16 e 17. A fim de quantificar o nível de contaminação do combustível, foi criada a norma ISO 4406 que estabelece um código numérico para cada faixa de quantidade de partículas de um determinado tamanho encontradas no exame da amostra.

No caso do sistema de injeção, partículas maiores que $4 \mu \mathrm{m}$ são particularmente críticas pelo seu potencial em passarem pelo filtro de combustível e em causar as falhas descritas. Por isso a Bosch define os requisitos mínimos de eficiência inicial de filtragem no veículo, definindo a porcentagem mínima inicial de retenção de partículas maiores que $4 \mu \mathrm{m}$.

Do outro lado, a Bosch procura conhecer a criticidade deste aspecto nos mercados onde atua através da pesquisa da SGS que, além de informar a quantidade de partículas por tamanho, também informa a classe ISO para partículas maiores que 4, 6 e $14 \mu \mathrm{m}$. Os mercados são classificados de acordo com o $80^{\circ}$ percentil dos resultados de ISO Code $>4 \mu \mathrm{m}$, ou seja, $80 \%$ dos resultados iguais ou melhores que aquele valor, sendo que:

- ISO Code $>4 \mu \mathrm{m} \leq 19$ : zona verde, equivalente à contaminação encontrada em mercados estabelecidos, como o Europeu, e sem casos frequentes de modos de falha atribuíveis a partículas.

- ISO Code $>4 \mu \mathrm{m}=20$ : zona amarela, considerado mercado de risco onde podem ocorrer casos de falhas devidos a partículas. Necessário sistema de filtragem robusto e com elevada eficiência inicial para evitar a ocorrência de falhas.

- ISO Code $>4 \mu \mathrm{m} \geq 21$ : zona vermelha, mercado considerado crítico, com falhas frequentes atribuíveis a partículas. Requer sistema de filtragem robusto e com elevada eficiência inicial.

Os dados da SGS para ISO Code $>4 \mu \mathrm{m}$ (figura 14) mostram que o Brasil tem melhorado neste aspecto ao longo dos últimos anos, possivelmente como resultado de ações das distribuidoras de combustíveis e da fiscalização da ANP (Agência Nacional do Petróleo). 
Na comparação entre postos com e sem bandeira (figura 15), o $80^{\circ}$ percentil dos resultados é melhor para os postos com bandeira, demonstrando os resultados positivos dos programas de qualidade do combustível adotados por estas redes. O resultado absoluto para estes postos com $80^{\circ}$ percentil próximo a 21 ainda os coloca na zona vermelha, mostrando que existe espaço para melhoria na logística e sistema de armazenamento do diesel comercial para evitar sua contaminação com partículas ou mesmo filtrando estas ainda no posto para evitar a obstrução precoce do filtro no veículo [7]. Comparando os resultados das amostras de S10 e S500, existe uma clara diferença de dois níveis de ISO Code. O S10, isoladamente, ficaria na zona amarela enquanto o S500 ficaria na zona vermelha, se mostrando bastante mais contaminado por partículas do que o S10. Este fato pode estar relacionado às melhores práticas dispensadas ao S10 desde sua introdução no mercado em 2013.

\begin{tabular}{|l|c|c|c|c|c|}
\hline \multirow{2}{*}{$\mathbf{8 0}^{\mathbf{0}}$ percentil } & Amostras & Amostras & \multicolumn{2}{|c|}{ ISO Code $>$ 4 $\mu m$} & \\
& S10 & S500 & S10 & S500 & Média \\
\hline Com bandeira & 12 & 14 & 19,8 & 21,4 & 20,6 \\
\hline Sem bandeira & 7 & 12 & 19,8 & 22,0 & 20,9 \\
\hline
\end{tabular}

Fonte: SGS

Figura 15 - Comparação do $80^{\circ}$ percentil entre postos com e sem bandeira e entre S10 e S500.

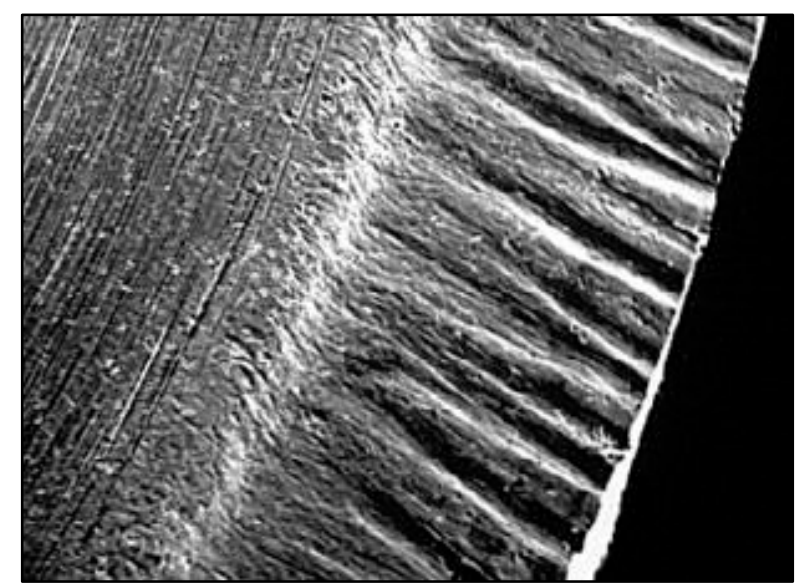

Fonte: Bosch

Figura 16 - Válvula de comando de bomba injetora com estrias causadas por partículas

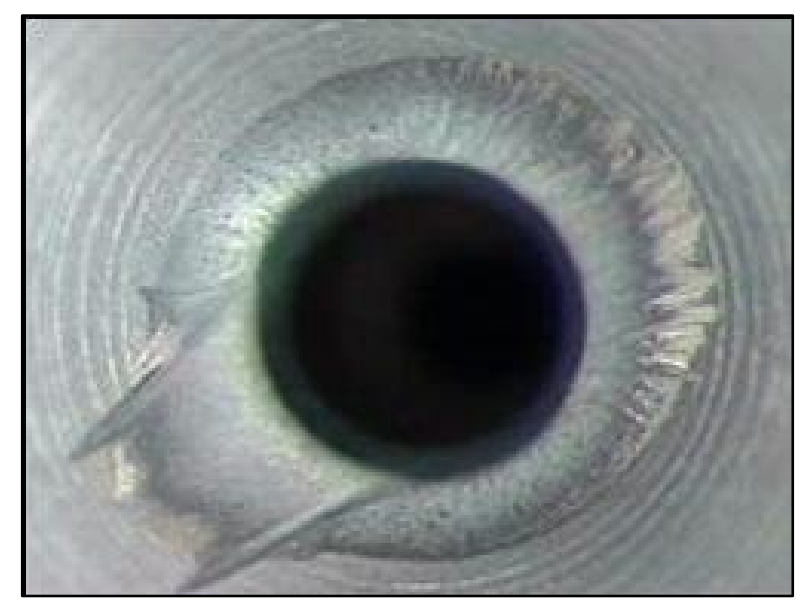

Fonte: Bosch

Figura 17 - Válvula de comando de injetor Common Rail com estrias causadas por partículas 
- Elementos químicos [mg/kg] - SGS M2534 (ICP)

A SGS também analisou a presença de diversos elementos químicos, dentre os quais aqueles com potencial efeito sobre o sistema de combustível e/ou de pós-tratamento de gases de escape são enumerados na tabela da figura abaixo:

\begin{tabular}{|l|l|c|c|c|}
\hline \multicolumn{2}{|c|}{ Elemento } & Mínimo & Média & Máximo \\
\hline Na & Sódio & 0,1 & 0,1 & 0,1 \\
\hline K & Potássio & 0 & 0 & 0 \\
\hline Ca & Cálcio & 0 & 0 & 0 \\
\hline Mg & Magnésio & 0 & 0 & 0 \\
\hline $\mathbf{P}$ & Fósforo & 0,1 & 0,24 & 0,7 \\
\hline Cu & Cobre & 0,1 & 0,13 & 0,2 \\
\hline Zn & Zinco & 0,1 & 0,23 & 0,3 \\
\hline
\end{tabular}

Figura 18 - Elementos químicos e suas concentrações nas amostras analisadas

Metais alcalinos, como o Sódio e Potássio, são utilizados na catálise da produção de biodiesel e como inibidores de corrosão em pipelines $(\mathrm{Na})$. Associados à formação de depósitos (sabões) no sistema de injeção, formação de cinzas e envenenamento de sistemas de pós-tratamento de gases de escape. A análise da SGS retornou valores de $0,1 \mathrm{mg} / \mathrm{kg}$ de Sódio em três amostras e nulos para as amostras restantes de Sódio e todas de Potássio, o que evita os potenciais problemas descritos.

Metais alcalinos terrosos, como o Cálcio e Magnésio, são utilizados como absorventes na produção de biodiesel. Associados à formação de depósitos (sabões) no sistema de injeção e envenenamento de sistemas de pós-tratamento de gases de escape. Sabões de Ca podem travar bombas injetoras. A análise da SGS retornou valores nulos para estes elementos, o que evita os potenciais problemas descritos.

O Fósforo é um componente natural de óleos vegetais (fosfolipídios). Tem alto poder de prejudicar os sistemas de pós-tratamento de gases de escape por desativar a superfície catalítica destes. Seu efeito é cumulativo, mesmo pequenas concentrações podem causar falhas prematuras ao longo do tempo. Tanto que a Europa recentemente reduziu o limite máximo de Fósforo de 8 para $4 \mathrm{mg} / \mathrm{kg}$. Quarenta amostras tiveram valores nulos, quatro amostras entre 0,1 e $0,2 \mathrm{mg} / \mathrm{kg}$ e uma última amostra com $0,7 \mathrm{mg} / \mathrm{kg}$. Partindo da premissa de que o Fósforo nesta amostra de B10 vem exclusivamente do biodiesel, o B100 utilizado tinha $7 \mathrm{mg} / \mathrm{kg}$, o que ainda está abaixo do limite brasileiro de $8 \mathrm{mg} / \mathrm{kg}$, mas que é excessivo para garantir a durabilidade de emissões de tecnologias para atendimento ao Proconve L7, L8 e P8.

Cobre e Zinco estão presentes em ligas não ferrosas (Zamac, Latão) e em superfícies zincadas no sistema de combustível (linhas, tanques, copos de filtros, etc.) tanto no abastecimento quanto no veículo. Apesar dos baixos valores máximos encontrados, de 0,2 e 0,3mg/kg respectivamente, estes são preocupantes por evidenciarem que componentes com estes elementos ainda são utilizados na cadeia logística do combustível. O Zinco é dissolvido da superfície do componente zincado pelo biodiesel e, na câmera de combustão, tem efeito cumulativo formando pesados depósitos no bico injetor e degradando sua função. O Cobre tem altíssimo potencial para catalisar a reação de oxidação do biodiesel, reduzindo esta em até 75\% em curto espaço de tempo [10]. Mesmo um biodiesel, com alta estabilidade à oxidação, terá ela reduzida rapidamente em contato com o cobre, mesmo que sejam pequenas superfícies. Assim, peças e conjuntos que contenham cobre, zinco e superfícies zincadas devem ser totalmente evitados. 
- Conteúdo de Biodiesel [\%v/v] - EN 14078

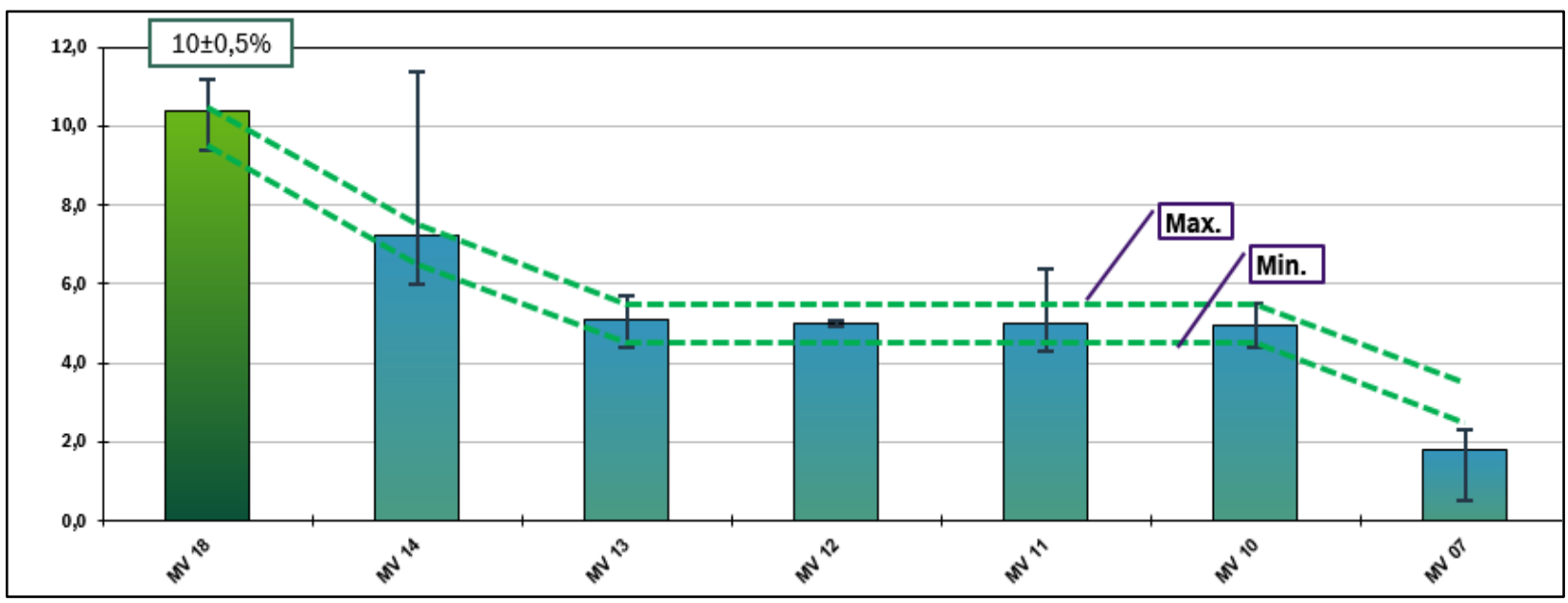

Fonte: SGS

Figura 19 - Análise da quantidade de biodiesel no Diesel entre os anos 2007 e 2018

O teor de biodiesel no diesel comercial evoluiu rapidamente nos últimos anos, sobretudo após a assinatura da Lei 13.263/2016 [1] que instituiu um calendário para aumento escalonado do teor de biodiesel após testes bem-sucedidos com misturas B10 e B15.

Atualmente, a mistura vigente para o diesel comercial brasileiro, é o B10 com variação permitida de $\pm 0,5 \%$, o que pôde ser comprovado pelos dados da SGS (figura 19). A média das amostras coletadas encontra-se próxima ao limite superior com 10,4\%. Ao todo oito postos, ou $18 \%$ das amostras, apresentaram misturas acima do limite de $10,5 \%$, sendo quatro bandeira branca e quatro com bandeira. Os casos extremos foram um posto na Bahia com 10,9\% e um posto no Mato Grosso do Sul com 11,2\%, ambos bandeira branca. As causas para tal desvio podem ser várias. Partindo da premissa de que não houve adulteração, a causa mais provável é a maior densidade do biodiesel que faz com que a porcentagem deste seja maior no fundo do que no topo do tanque de estocagem.

- Estabilidade à Oxidação [h] - EN 15751 (método Rancimat modificado)

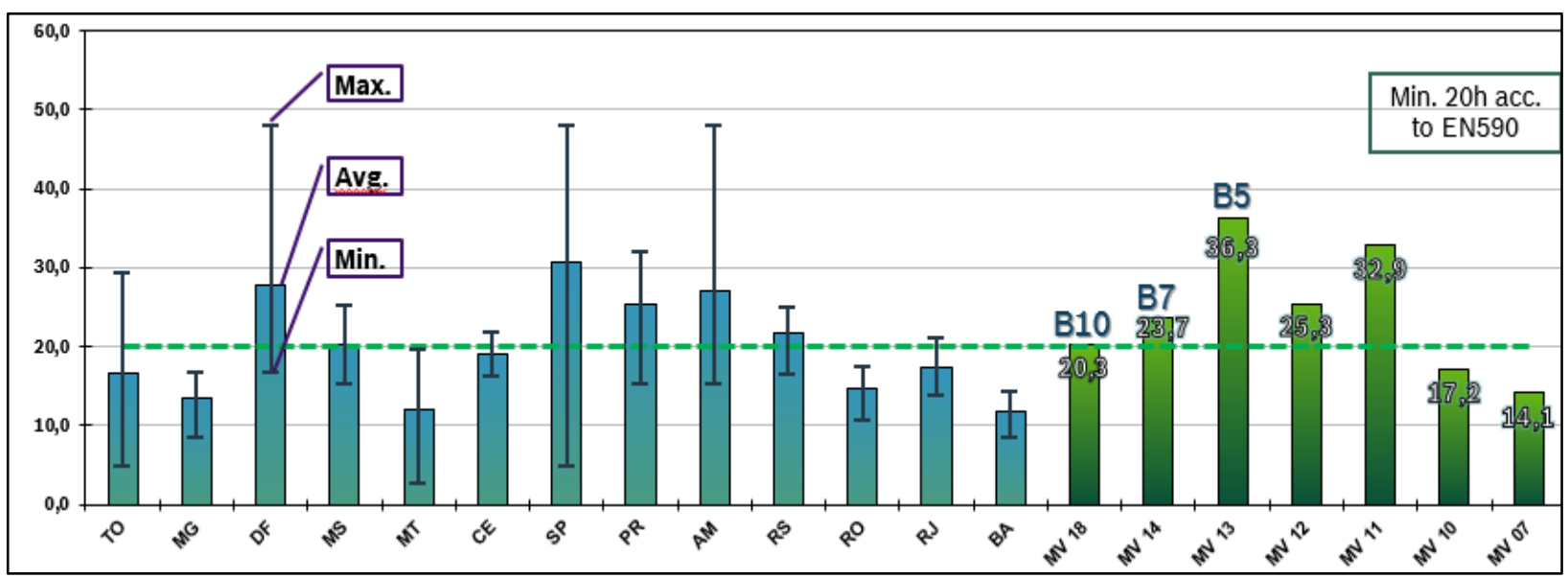

Fonte: SGS

Figura 20 - Análise estabilidade à oxidação do Diesel entre os anos 2007 e 2018 
O processo de envelhecimento do biodiesel e de suas misturas pode ser dividida em duas fases consecutivas [10]: na primeira ocorre a perda da estabilidade à oxidação, que é a propriedade que define a resistência do biodiesel contra as reações de degradação de suas moléculas. Nesta fase há pouca modificação química no combustível. Na segunda fase, ocorre o processo de envelhecimento propriamente dito, onde há alteração química no combustível gerando polímeros de envelhecimento e ácidos. A primeira fase pode ser mensurada de forma precisa através das metodologias EN 15751 - Rancimat modificado, cujos resultados são avaliados neste trabalho, e prEN 16091 - PetroOXY. Apesar de mais rápido que o Rancimat, o método PetroOXY ainda carece de estudos de correlação com o Rancimat para ser adotado nas especificações de diesel comercial [11]. Os produtos da segunda fase, polímeros de envelhecimento, também comumente chamados de borra (ASTM D 2274 [12] ou EN ISO 12205 [13] - sludge) ou ácidos de envelhecimento (IP 306 [14]) podem ser medidos quantitativamente. O total formado serve como indicativo do potencial de degradação de um combustível uma vez que seu envelhecimento tenha iniciado. Porém, avaliar o potencial de formação de borras é menos adequado para assegurar o correto funcionamento de um equipamento motorizado ou veículo uma vez que pequenas quantidades de borras geradas podem interromper o funcionamento do sistema de injeção diesel, colocando em cheque seus requisitos de alta performance pela formação de depósitos aderentes entre as diminutas folgas nas bombas e injetores de alta pressão. O objetivo deve ser, primordialmente, garantir que o combustível se mantenha estável, ou seja, não inicie seu processo de envelhecimento em toda a cadeia de abastecimento e que seja consumido antes que finde sua estabilidade à oxidação. Por isso este trabalho foca na estabilidade à oxidação das amostras colhidas pela SGS.

O gráfico da figura 20 traz os resultados de estabilidade à oxidação por unidade da federação e dos últimos anos. A linha tracejada verde representa o valor mínimo de estabilidade à oxidação encontrado na especificação europeia do diesel comercial B7 (EN 590 [15]). Este requisito não é encontrado na especificação brasileira do diesel comercial, Resolução ANP n ${ }^{\circ} 50$ de 2013 [16]. Na avaliação entre os estados brasileiros, existe uma grande diferença nos resultados encontrados e não é possível estabelecer uma tendência por regiões, demonstrando que a necessidade de melhoria da estabilidade à oxidação é nacional. A Bosch classifica os mercados em que atua em três classes de acordo com a estabilidade à oxidação para determinar o risco de ocorrência de problemas devido a depósitos de envelhecimento do combustível:

\begin{tabular}{|l|l|}
\hline Classe: & Estabilidade à oxidação segundo EN 15751 [h]: \\
\hline Seguro & $\geq 75 \% \mathrm{com} \geq 20 \mathrm{~h}$ \\
& $\& \geq 95 \% \mathrm{com} \geq 6 \mathrm{~h}$ \\
& $\& 0 \% \mathrm{com}<3 \mathrm{~h}$ \\
\hline Atenção & $\geq 95 \% \mathrm{com} \geq 6 \mathrm{~h}$ \\
& $\& 0 \% \mathrm{com}<3 \mathrm{~h}$ \\
\hline Alto Risco & Todos os outros resultados \\
\hline
\end{tabular}

Fonte: Bosch

Figura 21 - Classificação de mercados de acordo com a estabilidade à oxidação

Os resultados da SGS trouxeram que:

\begin{tabular}{|l|l|l|}
\hline $\begin{array}{l}\text { Faixa de estabilidade à } \\
\text { oxidação: }\end{array}$ & $\begin{array}{l}\text { Quantidades de } \\
\text { amostras: }\end{array}$ & Distribuição porcentual: \\
\hline$<3 \mathrm{~h}$ & 1 & $2,2 \%$ \\
\hline$>3 \&<6 \mathrm{~h}$ & 2 & $4,4 \%$ \\
\hline$>6$ \& $<20 \mathrm{~h}$ & 27 & $60,0 \%$ \\
\hline$>20 \mathrm{~h}$ & 15 & $33,3 \%$ \\
\hline
\end{tabular}

Figura 22 - Estatística dos resultados em cada faixa de estabilidade à oxidação 
Avaliando os resultados quanto à sua distribuição dentro das faixas de classificação (figura 22), observa-se que quase $7 \%$ das amostras estão dentro da faixa de alto risco e $60 \%$ na faixa de atenção, com somente um terço das amostras consideradas como seguras para uso, ou ainda 93,3\% com resultado acima de 6 horas e 2,2\% abaixo de 3 horas. Assim sendo, o Brasil fica classificado como mercado de alto risco para a ocorrência de falhas devido à formação de depósitos de oxidação e envelhecimento no sistema de combustível, ao lado de mercados como a Argentina e Estados Unidos da América.

Na avaliação mais detalhada dos dados da SGS, procurando uma correlação entre a baixa estabilidade à oxidação de algumas amostras com fatores que a possam influenciar, a figura 23 traz uma tabela comparando a estabilidade à oxidação de amostras de postos com e sem bandeira, bem como de amostras de S10 e S500. De forma análoga ao resultado da análise das partículas (ISO Code), os postos sem bandeira tiveram, na média, estabilidade à oxidação quase 5 horas ou 21\% menor que os postos com bandeira. Este fato pode ser, mais uma vez, explicado pelas melhores práticas adotadas pelas grandes redes varejistas de combustíveis. A comparação das amostras de S10 e S500 trouxe na média quase 6 horas ou 38\% a mais de estabilidade à oxidação para o S500 em relação ao S10. Este efeito foi observado em trabalhos internos da Bosch e explicado pelas diferenças entre as estruturas do S10 e S500 devido ao processo de retirada do enxofre que deixa o S10 menos resistente à oxidação térmica.

\begin{tabular}{|c|c|c|c|c|c|}
\hline & \multirow[t]{2}{*}{$\begin{array}{l}\text { Amostras } \\
\text { S10 }\end{array}$} & \multirow[t]{2}{*}{$\begin{array}{l}\text { Amostras } \\
\text { S500 }\end{array}$} & \multicolumn{2}{|c|}{$\begin{array}{c}\text { Média Estabilidade à } \\
\text { Oxidação [h] }\end{array}$} & \multirow[b]{2}{*}{ Média } \\
\hline & & & S10 & S500 & \\
\hline Com bandeira & 12 & 14 & 16,9 & 27,0 & 22,0 \\
\hline Sem bandeira & 7 & 12 & 16,1 & 18,5 & 17,3 \\
\hline & & Média & 16,5 & 22,8 & \\
\hline
\end{tabular}

Figura 23- Tabela com as comparações entre os dados de postos com e sem bandeira e S10 e S500

Ainda que a representatividade da análise de 45 amostras seja discutível em relação aos mais de 42.000 postos de abastecimento existentes no Brasil, ela serve para que se tenha uma noção sobre a qualidade do diesel comercial disponibilizado nestes postos e também à identificação de tendências ao longo do tempo. Nas barras de médias anuais da figura 20 fica evidente a queda da estabilidade à oxidação desde 2013 concomitante com o aumento do porcentual de biodiesel de B5 para B10. Esta tendência de queda e concomitância fica mais clara quando se avalia a figura 24, que traz uma maior frequência de amostragem (semestral) porém com menos amostras analisadas em cada amostragem, de 6 a 8 amostras. 


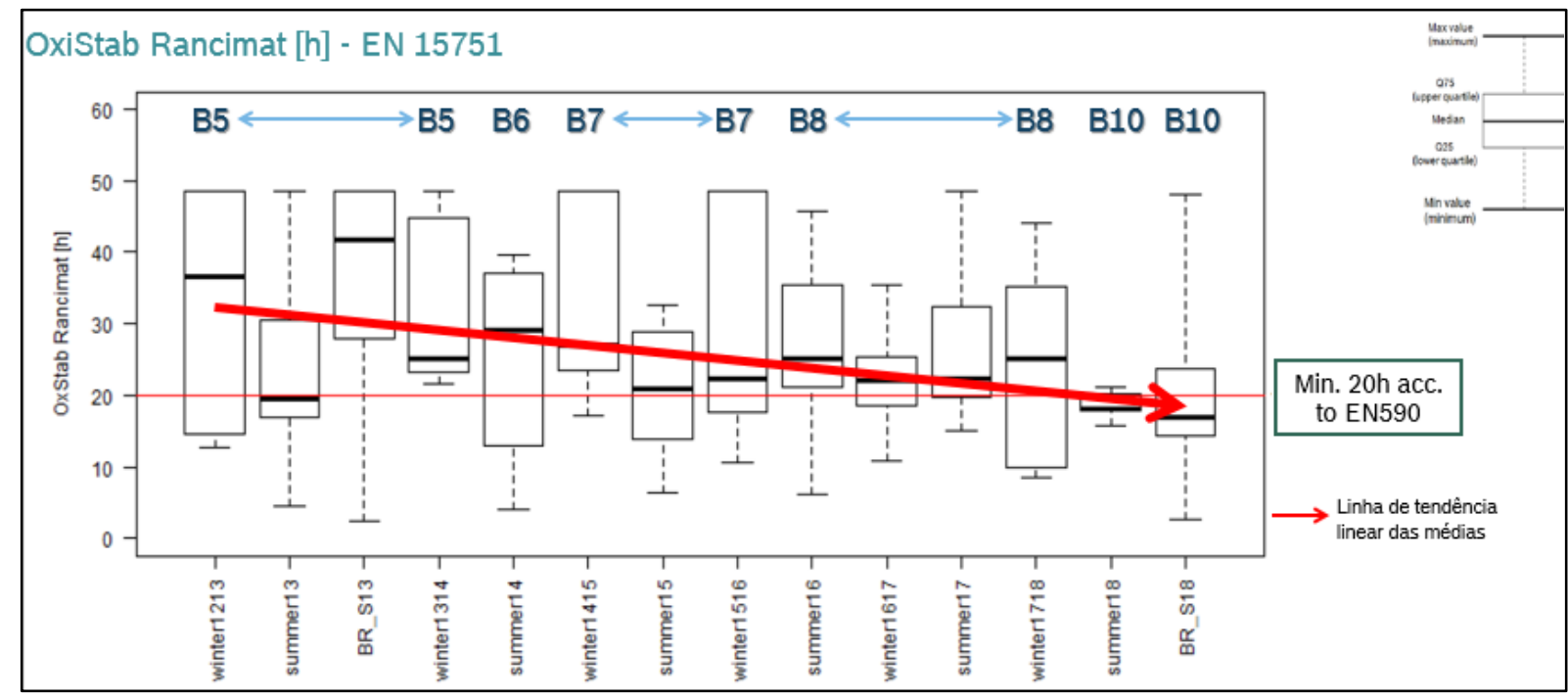

Fonte: SGS

Figura 24 - Análise da estabilidade à oxidação do Diesel com as mudanças na porcentagem de participação do biodiesel no diesel.

A redução da estabilidade à oxidação com consequente aumento de risco de falhas no sistema de combustível é confirmada pelas falhas ocorridas em veículos nos últimos anos, conforme exemplos retirados do workshop realizado pela AEA e ANP sobre qualidade de combustíveis em campo [17] mostrados nas figuras 25, 26 e 27.

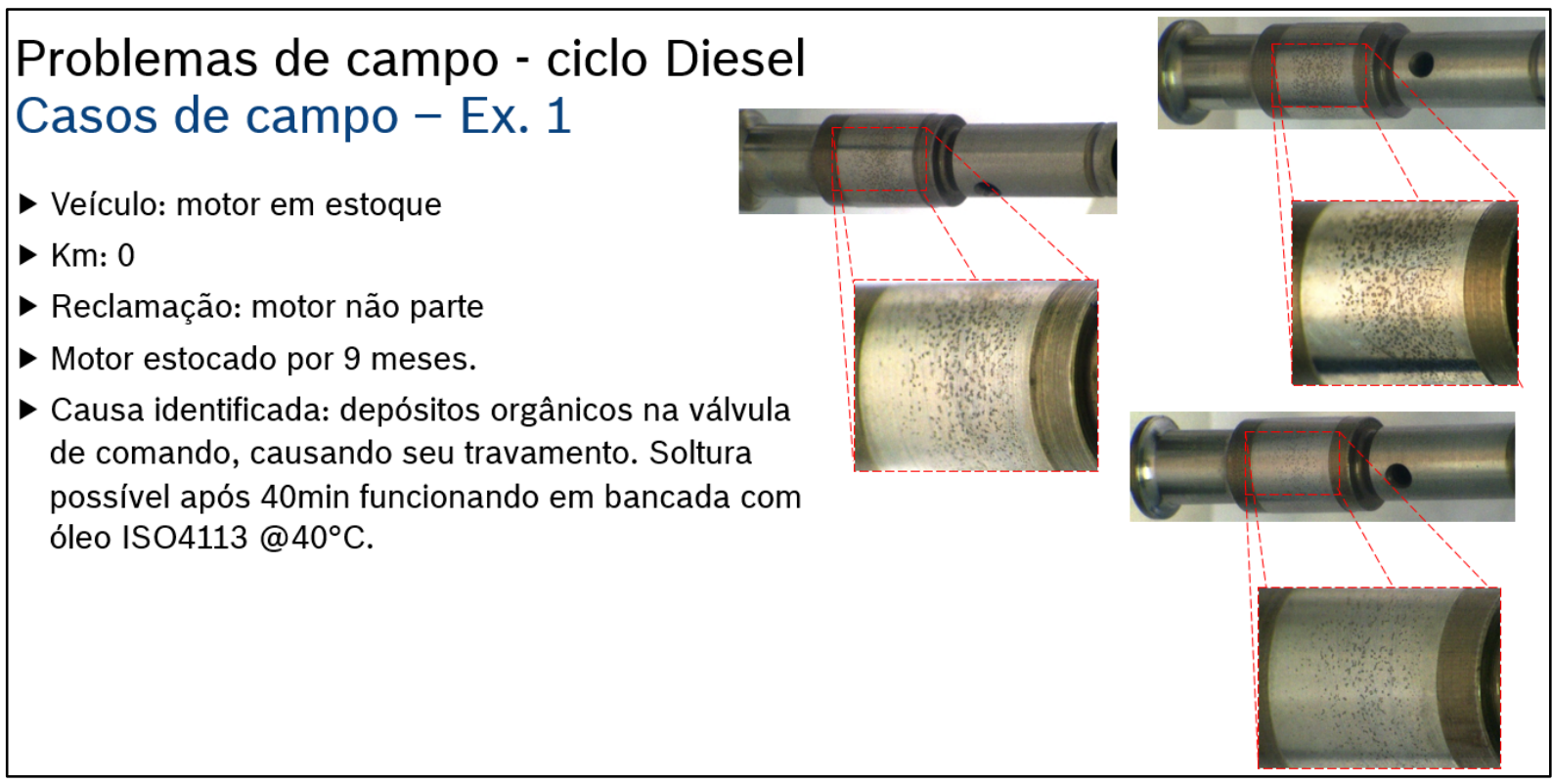

Fonte: Bosch

Figura 25 - Exemplo de falha de sistema de injeção em veículo 0km devido a depósitos de oxidação do biodiesel. 


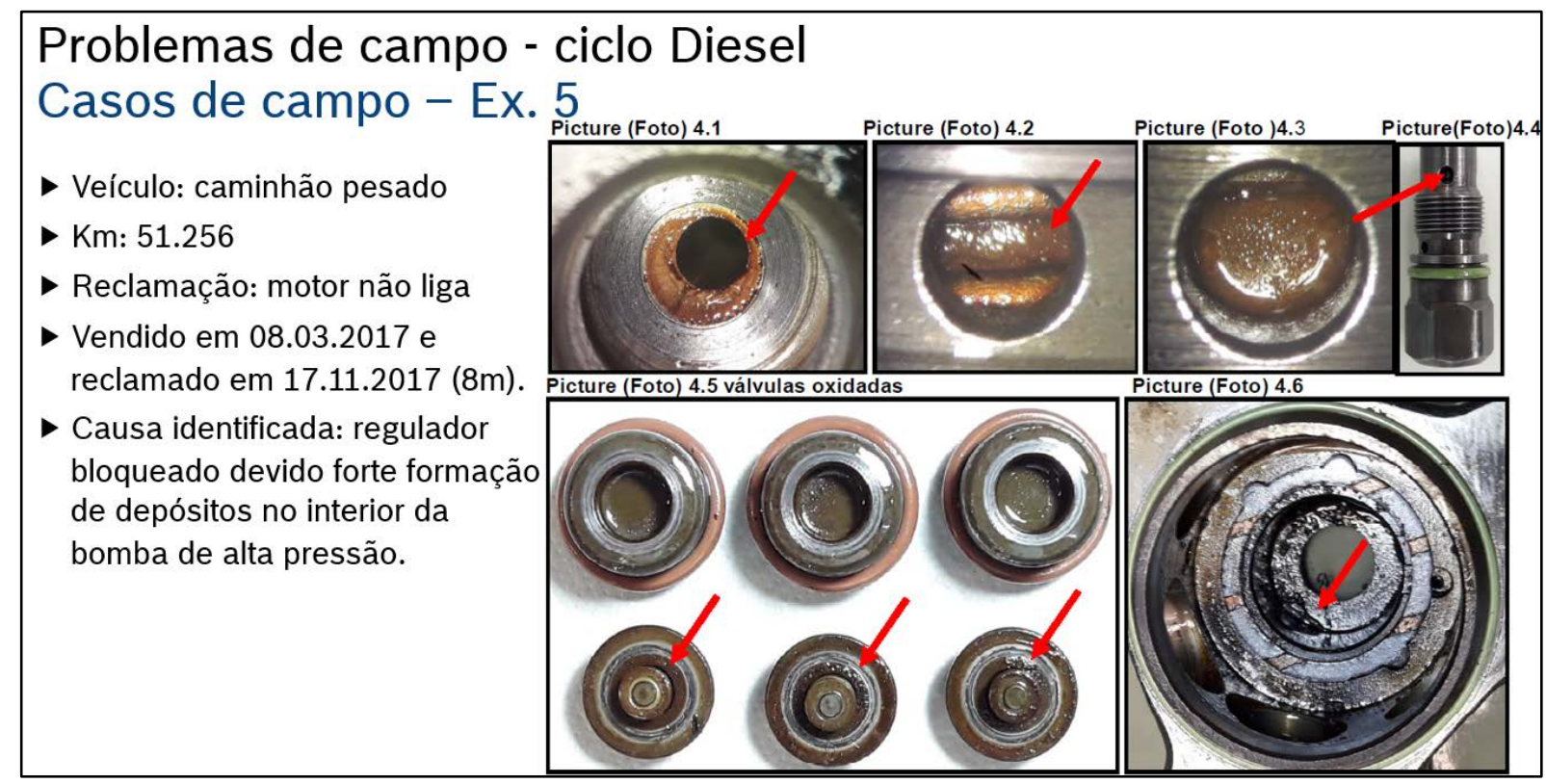

Fonte: Bosch

Figura 26 - Exemplo de falha de sistema de injeção em veículo com 8 meses de uso devido a depósitos de oxidação do biodiesel.

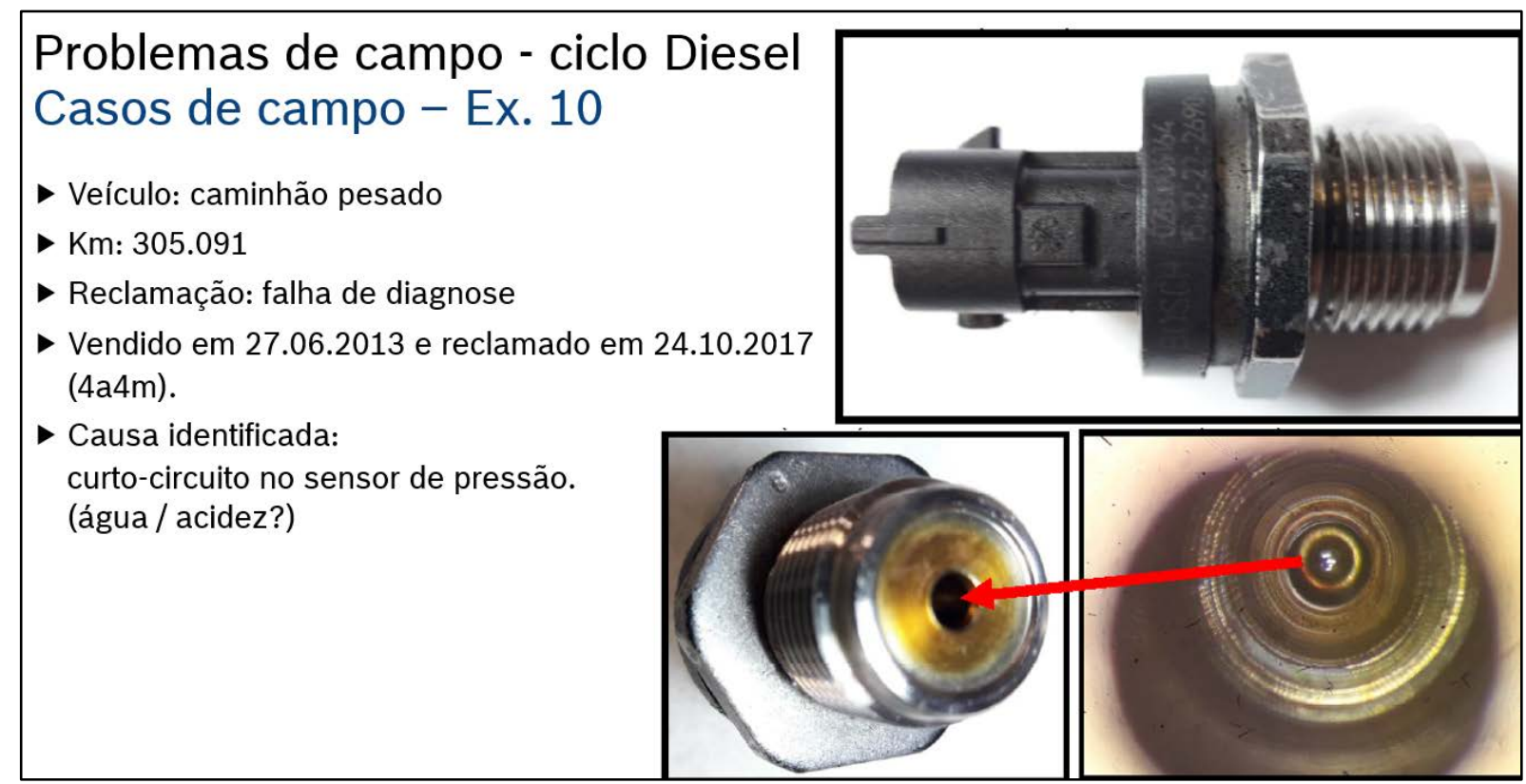

Fonte: Bosch

Figura 27 - Exemplo de falha de sistema de injeção em veículo com 4 anos e 4 meses de uso devido à água ou acidez do combustível e com depósitos de oxidação do biodiesel. 


\section{CONCLUSÃO}

A combinação das novas fases do PROCONVE, reduzindo drasticamente os limites de emissões de poluentes e aumentando as exigências de durabilidade de emissões e de controle destas, com as metas de eficiência do Rota2030 trazem requisitos exigentes e desafiadores dentro de um cenário de aumento da mistura de biodiesel promovido pelo Renovabio.

Neste cenário, a qualidade do diesel comercial é fundamental para garantir que as tecnologias atuais e futuras atendam a todos os requisitos legais, mas que sobretudo satisfaçam os usuários finais com a durabilidade e economia pelas quais a motorização diesel é conhecida.

A pesquisa de qualidade do diesel comercial trouxe resultados detalhados que possibilitaram uma análise rica em correlações destes dados com a experiência de campo.

Os destaques positivos ficam por conta das propriedades de viscosidade, densidade, lubricidade, curva de destilação e enxofre, que mostram um mercado maduro e que preenche as necessidades para atendimento aos requisitos legais e de durabilidade do sistema de injeção. Destaque à lubricidade, que, graças à parcela de biodiesel, teve excelentes resultados nos últimos anos, confirmados em campo pela ausência de falhas devido a esta propriedade.

Como pontos de atenção, ficam em destaque:

- Conteúdo de água: apesar de não ter resultados altos, continua causando falhas de campo. Para evita-las, é preciso não só melhorar o controle de água na cadeia logística, mas também a informação a mecânicos e proprietários de veículos leves a diesel, muitos dos quais desconhecem a presença do filtro separador de água e cuidados necessários.

- Cetano: apesar do desvio marginal nas amostras analisadas, é necessário investigar as possíveis causas para evitar desvios futuros.

- Elementos Químicos: a concentração de sódio, potássio, cálcio e magnésio foi nula ou perto disso, portanto seguro para uso. A concentração de fósforo, apesar de equivaler a uma concentração de 7ppm no B100, que tem limite de 8ppm, merece revisão futura para evitar o acúmulo deste elemento nos sistemas de pós-tratamento de gases de escape. A presença de zinco e cobre, apesar de pequena e em menos de $10 \%$ das amostras, é preocupante e deve ser evitada ao máximo devido às suas consequências sobre o combustível. É necessário rever as boas práticas e modernizar a cadeia logística dos combustíveis.

Como pontos críticos, podem ser destacados:

- Apesar da notável melhora na concentração de partículas sólidas maiores que $4 \mu \mathrm{m}$ nos últimos anos, o mercado brasileiro ainda se encontra na faixa crítica, requerendo medidas específicas de proteção nos veículos, por exemplo através de sistemas avançados e robustos de filtragem não requeridos em outros mercados. Aqui, mais uma vez, cabe uma revisão das melhores práticas, sobretudo na frequência de limpeza dos tanques de armazenamento nos postos de abastecimento.

- A estabilidade à oxidação apresenta queda concomitante com o aumento do teor de biodiesel dos últimos anos. Vários relatórios de testes do Sindipeças e da Anfavea com B10 e B15 ressaltam a importância de assegurar uma estabilidade à oxidação adequada. Enquanto os grupos de trabalho formados para o estudo deste assunto não chegam a uma conclusão, prevista para o final deste ano, algumas ações podem ser adotadas para prolongar a vida do diesel comercial:

o Levar ao usuário final o estado da arte em matéria de boas práticas, como por exemplo a cartilha de boas práticas criado pela Comissão Técnica de Diesel e Biodiesel da AEA disponível em http://aea.org.br/home/wpcontent/uploads/2018/12/Cartilha_Biodiesel_CT_AEA.pdf; 
o Certificar que metais catalíticos, especialmente o Cobre, não entrem em contato com o combustível;

o Minimizar o aquecimento do tanque de estocagem protegendo-o de incidência de luz solar direta ou pintando-o de branco;

o Evitar a contaminação com água utilizando filtros secantes no respiro e drenar a água do tanque de estocagem com frequência mínima semanal;

o Limpeza mecânica do tanque de estocagem para retirada da borra.

Mas os cuidados elencados acima não são suficientes caso a especificação do diesel comercial não seja adequada ao crescente teor de biodiesel para garantir sua robustez e ausência de falhas para o usuário final. Soluções como a adição de biocombustíveis de segunda geração, como o HVO, biodiesel de resíduos orgânicos e biodiesel de cana-de-açúcar podem se mostrar necessárias ao atingimento de metas ambientais e melhoria da qualidade do diesel comercial. É fundamental que o diálogo contínuo entre as partes interessadas da indústria, governo, incluindo agências reguladoras e produtores de combustíveis aconteça de forma a construir uma solução para a qualidade do diesel comercial que satisfaça as necessidades de durabilidade e economicidade dos usuários finais.

\section{REFERÊNCIAS}

[1] |CASA CIVIL DA PERSIDÊNCIA DA REPÚBLICA. LEI 13.263 de 23 de março de 2016. Disponível em http://www.planalto.gov.br/ccivil_03/_ato20152018/2016/lei/L13263.htm

\section{[2] MINISTÉRIO DE MINAS E ENERGIA.}

Relatório de consolidação dos testes para validação da utilização de misturas com Biodiesel B10 em motores e veículos. 30 de abril de 2018.

[3] MINISTÉRIO DE MINAS E ENERGIA. Relatório de consolidação dos testes e ensaios para validação da utilização de Biodiesel B15 em motores e veículos. 28 de fevereiro de 2019. [4]A SGS DE FORMA RESUMIDA. Disponível em https://www.sgsgroup.com.br/pt-br/ourcompany/about-sgs/sgs-in-brief. Acesso em:10 de maio de 2019.

[5] SHMITT, Jennifer; WERNER, Sabine. SGS 2018. Local: SGS, novembro de 2018.

[6] AURÉLIO FELLER, Marco. Óleo diesel, suas propriedades e respectivas influencias. Monografia de especialização, Curitiba, 2011.

[7] OLIVEIRA GOMES, Helinéia; DA SILVA, Raíssa; ROCHA, Mauro Iurk; WAHNFRIED, Christian Michael; BOLDO, Carlos Antônio. Influência tribológica do óleo diesel sobre sistemas de injeção. SIMEA 2003.

[8] PROPRIEDADES FÍSICAS E QUÍMICAS DO BIODIESEL. Disponível em https://www.biodieselbr.com/biodiesel/especificacoes/biodiesel-propriedades-fisicasquimicas. Acesso em 15/05/2019.

[9] PROJAHN, Ulrich; KRIEGER, Klaus; DABAGUE, Ricardo; BOLDO, Carlos. Qualidade do combustível diesel - visão geral do ponto de vista dos fabricantes de sistemas de injeção. SIMEA 2001 e apresentado em vários seminários posteriores.

[10] ULLMANN, Jörg, EPPINGER, Dieter, STUTZENBERGER, Heinz. Factors influencing fuel ageing - conclusions from laboratory experiments and investigations in vehicles. TAE Fuels 8th International Colloquium, January 2011, pp. 99 - 107

[11] CEN/TR 17225 - Fuels and biofuels - Assessment on oxidation stability determination methods for distillate fuels and blends thereof with fatty acid methyl esters (FAME).

Setembro de 2018. 
[12] ASTM D 2274 - 10, Test Method for Oxidation Stability of Distillate Fuel Oil (Accelerated Method)

[13] EN ISO 12205:1996, Petroleum products - Determination of the oxidation stability of middle-distillate fuels (ISO 12205:1995)

[14] IP 306:1994, Determination of oxidation stability of straight mineral oil, BSI

[15] DIN EN 590:2017-10. Automotive fuels - Diesel - Requirements and test methods.

[16] AGÊNCIA NACIONAL DO PETRÓLEO, GÁS NATURAL E BIOCOMBUSTÍVEIS.

Resolução ANP No 50, DE 23.12.2013

[17] WAHNFRIED, Christian Michael. Problemas de campo no brasil com motores e veículos do ciclo Diesel, apresentação no Workshop ANP \& AEA - Combustíveis:

Características, Qualidade e Consequências no Campo. Rio de Janeiro, 19 de junho de 2018. 